\title{
ANALISIS STRATEGI PENGELOLAAN EKOSISTEM TERUMBU KARANG DI KAWASAN KONSERVASI PERAIRAN DAERAH LIUKANG TUPPABIRING
}

\author{
(Analysis of Coral Reff Management Strategy In Liukang Tuppabiring \\ Region The Water Conservation Area) \\ Tenri A.R 1), Danial ${ }^{2)}$ dan Asbar 2) \\ 1) Mahasiswa Pasca-Sarjana Universitas Muslim Indonesia \\ 2) Dosen Program Manajemen Pesisir dan Teknologi Kelautan UMI Makassar
}

Korespondensi: tenriar76@yahoo.com

Diterima: 12 Agustus 2020; Disetujui 20 November 2020

\begin{abstract}
Liukang Tuppabiring is a waters with marine biodiversity potential large enough to be developed and managed sustainably. Utilization around the coral reefs in the waters of the Liukang Tuppabiring sub-district currently tends to lead to destructive use, so it is necessary to take damage prevention measures immediately. The results showed the condition of coral cover in the medium and damaged, while at stations 1,2,3,4,6 (25,47-41.07\%), while conditions were good at station $5(56.20 \%)$. The number of individual reef fish is 290 individuals from 46 species of 22 genera 11 families. At the research location also identified one type of protected biota namely Hawksbill (Eretmochelys imbricata). Coral damage that occurred at 6 observation stations was more caused by the practice of using destructive and environmentally unfriendly fishing equipment such as bombs, trawls, and the use of poisons. The priority strategies undertaken in the management of coral reefs at the study site are 1) Management of environmentally friendly coral reefs where the community as a manager with strong support from the Government; 2) Making clear rules related to utilization in coral reef areas and establishing a POSMAKWAS institution to avoid more severe coral damage; 3) Improve supervision and law enforcement must be firm in relation to the use of fishing gear that can damage coral reef ecosystems.
\end{abstract}

Keywords: Liukang Tuppabiring, Coral Reef, Ecosystem Management, Hawksbill turtles

\begin{abstract}
ABSTRAK
Liukang Tuppabiring merupakan perairan dengan potensi keanekaragaman hayati laut yang cukup besar untuk dikembangkan dan dikelola secara berkelanjutan. Pemanfaatan di sekitar terumbu karang di perairan kecamatan Liukang Tuppabiring saat ini cenderung mengarah pada pemanfaatan yang merusak sehingga perlu segera dilakukan tindakan pencegahan kerusakan. Hasil penelitian didapatkan kondisi tutupan karang dalam kategori baik dan sedang, sedang di stasiun 1, 2, 3, 4 dan 6 (35,89-41,07\%), sedangkan kondisi baik di stasiun 5 (56,20\%). Jumlah individu ikan karang yaitu 290 individu dari 46 spesies 22 genus 11 famili. Di lokasi penelitian juga teridentifikasi satu jenis biota dilindungi yakni Penyu sisik (Eretmochelys imbricata). Kerusakan karang yang terjadi pada 6 stasiun pengamatan lebih disebabkan karena praktik penggunaan peralatan tangkap yang sifatnya destruktif dan tidak ramah lingkungan seperti bom, trawll, dan penggunaan racun. Strategi prioritas yang dilakukan dalam pengelolaan terumbu karang pada lokasi penelitian adalah 1) Pengelolaan terumbu karang yang ramah lingkungan dimana masyarakat sebagai pengelola dengan dukungan kuat dari Pemerintah; 2) Membuat aturan yang jelas terkait pemanfaatan di kawasan terumbu karang serta membentuk lembaga POSMAKWAS untuk menghindari kerusakan karang yang lebih parah; 3) Meningkatkan pengawasan dan penegakan hukum harus tegas terkait penggunaan alat tangkap yang dapat merusak ekosistem terumbu karang.
\end{abstract}

Kata kunci: Liukang Tuppabiring, Terumbu Karang, Pengelolaan Ekosistem, Penyu sisik 


\section{PENDAHULUAN}

Kecamatan Liukang Tuppabiring memilki luas wilayah $60 \mathrm{~km}^{2}$ dan secara geografis kecamatan ini berada diantara 04039'0.36" - 040 $58^{\prime} 7.68^{\prime \prime}$ LS dan $118^{0} 56^{\prime} 56,4$ - $119^{0} 58^{\prime} 7.68^{\prime \prime}$ BT. Kecamatan Liukang Tuppabiring terdiri dari 9 Desa/Kelurahan. Liukang Tuppabiring dikategorikan sebagai kecamatan kepulauan oleh karena wilayahnya berupa pulau-pulau kecil dan sebagian besar merupakan perairan laut. Dalam wilayahnya terdapat 42 pulau dimana 31 pulau diantaranya berpenghuni dan 11 pulau tidak berpenghuni (BPS Pangkep, 2019)

Kecamatan Liukang Tuppabiring merupakan salah satu kecamatan dengan potensi keanakaragaman hayati laut yang cukup besar untuk dikembangkan dan dikelola secara berkelanjutan. Terdapat beberapa keanekaragaman hayati berupa keanekaragaman spesies ikan karang yang memiliki nilai ekonomis penting dan keanekaragaman ekosistem seperti ekosistem terumbu karang, dan lamun serta beberapa biota dilindungi seperti penyu dan bambu laut.

Memiliki potensi sumberdaya hayati yang cukup besar dan didukung wilayah perairan yang strategis sehingga menyebabkan perairan Liukang
Tuppabiring rawan akan dieksploitasi secara berlebihan terhadap sumberdaya hayati ekosistem yang ada khususnya ekosistem terumbu karang. Pemanfaatan di sekitar terumbu karang di perairan kecamatan Liukang Tuppabiring saat ini cenderung mengarah pada pemanfaatan yang merusak sehingga perlu segera dilakukan tindakan pencegahan kerusakan.

Luasnya terumbu karang di perairan Liukang Tuppabiring serta perairan laut Tuppabiring yang open acces dimanfaatkan dengan cara-cara yang tidak ramah lingkungan oleh para nelayan setempat. Hasil monitoring yang telah dilakukan oleh team LIPI tahun 2012 rata-rata kondisi karang di beberapa gosung atau pulau-pulau kecil di perairan Tuppabiring telah banyak mengalami kerusakan yang cukup parah. Secara umum kondisi terumbu karang di 19 stasiun yang telah dilakukan oleh LIPI sebesar 42,68\% (Manuputty, 2012)

Data yang ada saat ini tidak dapat memberikan gambaran secara pasti terkait kondisi terumbu karang yang terdapat di perairan Tuppabiring. Berdasarkan hal tersebut maka dari itu diperlukan sebuah data terkini terkait kondisi terumbu karang dan biota asosiasi di kawasan konservasi Liukang 
Tuppabiring agar dapat diketahui model pengelolaan terumbu karang yang akan dilakukan di kawasan konservasi tersebut.

\section{METODE PENELITIAN}

\subsection{Waktu dan Tempat Penelitian}

Kegiatan penelitian ini dilakukan bulan Maret - April 2020, di Pulau Cangke dan Pulau Polewali Kecamatan Liukang Tuppabiring Kabupaten Pangkajene Kepulauan Provinsi Sulawesi Selatan.

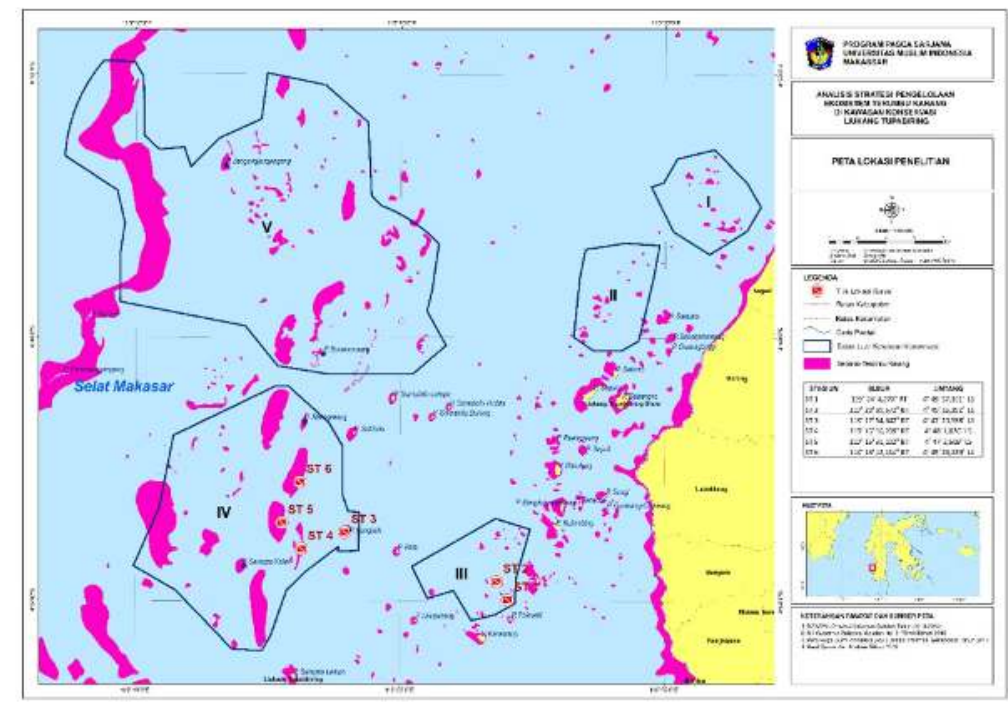

Gambar 1. Peta lokasi penelitian

\subsection{Alat dan Bahan}

Alat dan bahan yang digunakan dalam penelitian ini yaitu alat selam (SCUBA diving), alat tulis dan kamera bawah air, GPS untuk penentuan posisi stasiun, thermometer untuk mengukur suhu perairan, handrefraktometer untuk mengukur salinitas, layangan arus untuk menetukan kecepatan arus, secchi disk untuk mengukur tingkat kecerahan, aplikasi GIS, Peta RBI Skala 1:50.000 BIG tahun 2017, Citra Satelit SPOT 6 tahun 2017.

\subsection{Jenis dan Sumber Data}

Data dari penelitian ini terdiri dari data primer dan data sekunder. Data primer hasil dari survei berupa data kondisi terumbu karang, data kualitas perairan, dan sosial budaya masyarakat, sedangkan data sekunder berupa data yang diperoleh dari instansi terkait berupa data kependudukan serta peraturan daerah terkait KKPD Liukang Tuppabiring. 
1.4. Sumber Data dan Metode Census, UVC), pada bidang

\section{Pengumpulan Data}

Dalam penelitian ini sumber data berasal dari data sekunder dan data primer. Data sekunder diperoleh dari hasil desk study dari berbagai informasi kepustakaan yang terkait dengan lokasi dan tujuan penelitian, sedangkan data primer yang merupakan data eksisting berasal dari hasil observasi dan survey data lapang di lokasi penelitian yang mencakup asepk ekologi.

\section{Terumbu Karang}

Pengambilan data ekosistem terumbu karang dilakukan dengan penyelaman menggunakan peralatan selam SCUBA dengan metode UPT (Underwater Photo Transect $=$ Transek Foto Bawah Air) Giyanto et al., 2010; Giyanto, 2012a; Giyanto, 2012b).

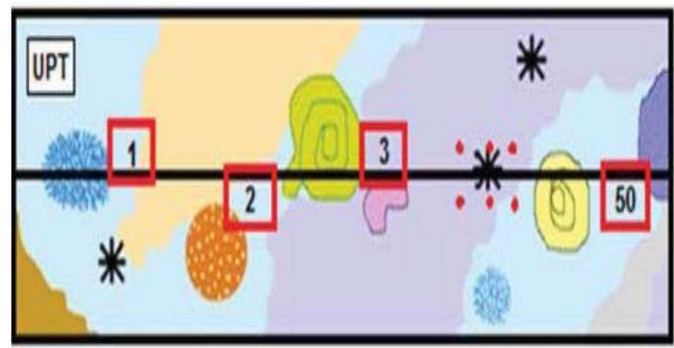

Gambar 2. Ilustrasi Dalam Penarikan Sampel

\section{Ikan Karang}

Pengamatan ikan di terumbu karang dilakukan di lokasi transek yang sama dengan pengamatan karang. Metode yang digunakan ialah sensus visual (Under water Fish Visual pengamatan seluas $5 \times 1 \quad 25$ meter persegi. Pengamatan dilakukan disepanjang garis transek dengan jarak pandang sejauh 2,5 $\mathrm{m}$ ke sebelah kiri dan 2,5 meter ke sebelah kanan garis transek.

\section{Sosial Ekonomi Masyarakat}

Data sosial kemasyarakatan merupakan data yang dibutuhkan untuk mengetahui persepsi masyarakat lokal maupun pemerintah setempat terkait pengelolaan ekosistem terumbu karang Pengumpulan data mealui kuisioner dan wancara.

\subsection{Analisis Data}

Dalam penelitian ini terdapat beberapa analisis yang digunakan untuk menjawab seluruh tujuan penelitian

\section{Analisis Deskriptif}

Analisis ini dilakukan untuk mengetahui realitas kondisi ekosistem pesisir, kondisi sosial ekonomi dan budaya masyarakat pesisir yang berkaitan dengan pemanfaatan sumberdaya pesisir dan laut yang telah dilakukan di lokasi penelitian.

\section{Analisis Kondisi Karang}

Analisis foto berdasarkan foto hasil pemotretan dilakukan menggunakan komputer dan piranti lunak (software) CPCe. Jumlah titik acak yang digunakan adalah sebanyak 30 buah 
untuk setiap framenya, dan ini sudah representatif untuk menduga persentase tutupan kategori dan substrat (Giyanto et al.,2010). Persentase tutupan setiap foto frame dihitung berdasarkan rumus sebagai berikut:

$$
\%=\frac{\text { Jumlah kategori }}{\text { Banyak titik acak }} \times 100 \%
$$

Status kondisi rusak (0-24,9\%), sedang (25-49,9\%), baik (50-74,9\%) dan sangat baik (75-100\%) (Gomez dan Yap,1 988).

\section{Analisis SWOT}

Untuk menjawab rumusan masalah ketiga yaitu bagaimana pengelolaan terumbu karang di kawasan konservasi Liukang Tuppabiring, dilakukan analisis data digunakan analisis deskriptif kualititatif melalui wawancara dengan para informan yang terlibat. Untuk merumuskan strategi pengelolaan, digunakan analisis SWOT. Matriks Strengths Weaknesses Opportunities Threats (SWOT) merupakan matching tool yang penting untuk membantu para manajer mengembangkan empat strategi (David, 2009).

\section{HASIL DAN PEMBAHASAN}

\section{Kondisi Umum Lokasi}

Secara administrasi KKPD Liukang Tuppabiring berada di Kecamatan Liukang Tuppabiring dengan lokasi kawasan sebagian besar merupakan gosong-gosong karang pada pulaupulau kecil seperti Pulau Reangreang, Pulau Jangangjangangngan, Pulau Polewali dan Pulau Cangke.

Kecamatan Liukang Tuppabiring dicadangkan melalui Keputusan Gubernur Sulawesi Selatan Nomor 3172/XII/2018 dengan nama KKPD Tuppabiring. Luas kawasan yang dicadangkan adalah 66.870 ha dengan jenis kawasan yakni Taman Pesisir.

\section{b. Kondisi Fisik Perairan}

\section{Arus}

Kecepatan arus di perairan Liukang Tuppabiring terlihat bahwa kecepatan arus maksimum terjadi pada bulan Februari, April, Agustus, Oktober dan Desember dengan kecepatan arus mencapai $0,41-0,50 \mathrm{~m} / \mathrm{s}$ dan minimum pada bulan Januari dan Juni dengan kecepatan 0,08-0,21 m/s.

\section{Pasang Surut}

Pasang surut lokasi penelitian memiliki tipe campuran yang cenderung bersifat harian ganda (mixed prevailing semi diurnal). Dalam satu hari terjadi dua kali air pasang dan dua kali air surut. Di perairan Kecamatan Liukang Tuppabiring Kabupaten Pangkajene Kepulauan, kisaran pasang surut harian pada tanggal 23 Juli 2019 mencapai pasang tertinggi 1,30 meter (pukul

08.05). 


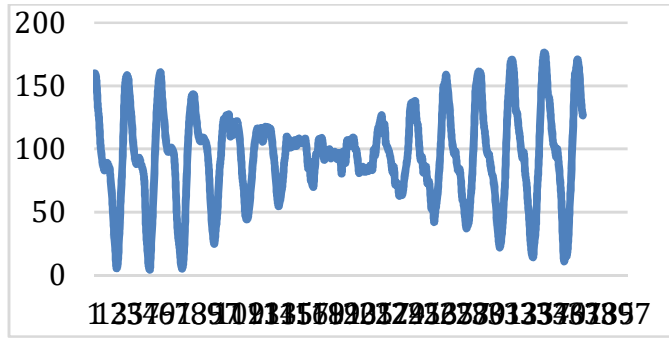

Gambar 3. Fluktuasi Pasang Surut selama 1 bulan

\section{Gelombang}

Di Kawasan Konseversi Perairan Daerah Liukang Tuppabiring, arah dan besarnya ombak sangat tergantung pada musim. Kondisi gelombang yang tenang di perairan Liukang Tuppabiring terjadi pada periode musim barat dengan tinggi gelombang berkisar antara 1.40-2.10 meter. Musim timur di perairan barat Sulawesi Selatan khususnya di Liukang Tuppabiring tinggi gelombang 1,25 1,5 meter.

\section{c. Kondisi Kualitas Air}

Hasil analisis perkiraan selama 10 tahun terakhir di perairan Spermonde khususnya Liukang Tuppabiring menunjukan kisaran suhu berada pada kisaran $29-30^{\circ} \mathrm{C}$. Kondisi suhu yang demikian masih sesuai dengan baku mutu menurut Keputusan Menteri Lingkungan Hidup No 51 tahun 2004 yaitu alami $\left(28-30^{\circ} \mathrm{C}\right)$

Data insitu nilai potensi derajat keasaman untuk lokasi penelitian berkisar antara 7,3 - 7,8 relatif homogen. Nilai $\mathrm{pH}$ yang demikian merupakan $\mathrm{pH}$ yang stabil dan sangat baik dalam mendukung pertumbuhan ekosistem terumbu karang di lokasi penelitian.

Hasil pengukuran salinitas di lokasi penelitian berada pada kisaran 31-33 PSU. Sebaran parameter salinitas di lokasi penelitian tidak terdapat perbedaan pada musim timur (kemarau) dan musim barat (hujan). Salinitas yang terdapat di perairan ini relatif stabil tiap tahunnya sehingga sangat mendukung untuk pertumbuhan/perkembangan ekosistem dan biota asosiasi.

\section{d. Kondisi Terumbu Karang}

Terumbu karang di perairan KKPD Tuppabiring tersebar secara spot-spot membentuk sebuah karang gosong (patch reef) dengan luasan yang sangat luas yakni 6.753,11 ha.

Berdasarkan hasil pengamatan dan analisis data lapangan yang telah dilakukan, pada umumnya kondisi terumbu karang di 6 stasiun pengamatan berada dalam kategori kondisi baik dan sedang.

Tabel 1. Kondisi Terumbu Karang Masing-Masing Stasiun

\begin{tabular}{cccc}
\hline Titik & $\begin{array}{c}\text { Karang } \\
\text { Hidup }\end{array}$ & $\begin{array}{c}\text { Karang } \\
\text { Mati }\end{array}$ & Kondisi \\
\hline 1 & 39,67 & 16,07 & Sedang \\
\hline 2 & 36,93 & 32,33 & Sedang \\
\hline 3 & 41,07 & 33,40 & Sedang \\
\hline 4 & 35,89 & 33,96 & Sedang \\
\hline 5 & 56,20 & 23,07 & Baik \\
\hline 6 & 25,47 & 30,27 & Sedang \\
\hline
\end{tabular}


Sumber : Hasil survei, 2020

Kondisi terumbu karang di 6 stasiun pengamatan masuk dalam kategori sedang dengan nilai rata-rata persentase karang hidup 39,21\%. Karang dengan kategori baik tercatat terdapat di stasiun 5 Pulau Cangke dengan persentase karang hidup $56,20 \%$, karang dengan kategori sedang dijumpai di stasiun 1 dan 2 Pulau Polewali serta stasiun 3, 4 dan 6 Pulau Cangke (25,47-41,07\%). Hasil analisis yang dilakukan didapatkan pertumbuhan karang yang teridentifikasi umumnya didominasi oleh bentuk pertumbuhan coral massive (CM), coral branching (CB), coral encrusting (CE), serta beberapa karang bercabang dari genus acropora.

Selain komponen karang hidup, komponen karang mati di lokasi penelitian juga cukup tinggi dimana nilai kisaran tutupan karang mati adalah 16,07-33,40\% dengan nilai ratarata $28,13 \%$. Tingginya komponen DCA yang terdapat di tiap stasiun merupakan refleksi dari karang mati dalam bentuk utuh dan telah terjadi dalam waktu yang sudah cukup lama. Karang mati yang ditumbuhi alga bisa jadi disebabkan oleh proses sedimentasi yang berlangsung secara terus menerus di stasiun ini. Hasil penelitian Partini (2009), didapatkan hasil bahwa dari analisis regresi yang dilakukan, laju sedimentasi berpengaruh positif terhadap indeks mortalitas terumbu karang. Semakin tinggi sedimentasi, semakin tinggi pula tingkat kematian terumbu karang. Setiap terjadi peningkatan satu satuan sedimentasi akan menyebabkan sebesar 0,002 indeks kematian.

\section{e. Kelimpahan Ikan Karang}

Total jumlah individu ikan karang di lokasi penelitian sebanyak 290 individu. Secara umum berdasarkan kriteria kelimpahan ikan karang yang dikemukakan oleh Manuputty (2009) untuk 6 stasiun pengamatan di KKPD Tuppabiring masuk dalam kategori ikan "Banyak" karena jumlah ikan targetnya lebih dari 100 individu.

- Jumlah individu ikan mayor adalah 1366 individu yang didominasi oleh famili Pomacentridae (119 individu)

- Jumlah individu ikan target yakni 114 individu yang didominasi oleh famili, Acanthuridae dan Scaridae yang memiliki masing-masing nilai kelimpahan 40 individu.

- Jumlah individu ikan indikator sebanyak 40 individu dari famili Chaetodontidae. Jumlah spesies ikan indikator yang berhasil diidentifikasi sebanyak 11 jenis yang didominasi oleh Chaetodon Octofasciatus (8 individu), Chaetodon triangulum 
dan Chaetodon baronessa 4 individu

\section{f. Biota Dilindungi}

Perairan Liukang Tuppabiring disinyalir merupakan area migrasi berbagai jenis penyu. Pulau-pulau kecil di Kecamatan Liukang Tuppabiring khususnya di Pulau Cangke yang banyak di dominasi pantai berpasir menjadikannya sebagai lokasi ideal untuk nesting ground. Adapun jenis penyu yang melakukan proses bertelur di Pulau ini adalah jenis Penyu sisik (Eretmochelys imbricata)

\section{g. Kondisi Sosial Masyarakat}

Pada wilayah perairan Kecamatan Liukang Tuppabiring khususnya di lokasi penelitian merupakan wilayah yang ditempati dari etnis suku Bugis, Bugis Makassar, serta Suku Mandar yang tinggal dan beradaptasi satu sama lain di wilayah tersebut.

Pola kehidupan masyarakat pesisir khususnya masyarakat nelayan di wilayah penelitian kehidupan masyarakat pesisir yang masih jauh dari akses teknologi menyebabkan kegiatan masyarakat pesisir masih berperilaku dengan tradisi-tradisi budaya yang mereka percayai sebagai produk dari kehidupan leluhur mereka. Model kegiatan kenelayanan masyarakat pesisir di perairan Tuppabiring dengan mengandalkan tanda-tanda alam untuk melakukan aktivitas perikanan tangkap, pada khususnya memberikan efek terhadap tata cara kehidupan masyarakat nelayan di Kecamatan tersebut.

\section{h. Faktor Penyebab Kerusakan Terumbu Karang}

Penurunan kualitas terumbu karang di kawasan tersebut berdasarkan bentuk kerusakannya yang tampak adalah disebabkan oleh beberapa hal :

a) Terumbu karang yang rusak dalam bentuk patahan-patahan karang dengan ukuran kecil merupakan ciriciri bahwa terumbu karang di wilayah tersebut telah mendapatkan tekanan dari eksploitasi yang menggunakan bahan peledak.

b) Banyaknya dijumpai terumbu karang tertutup sedimen dan algae, hal ini di mungkinkan karena tingginya tingkat sedimentasi dan kekeruhan perairan yang menyebabkan kurangnya penetrasi cahaya matahari yang diperlukan zooxanthellae dan karang untuk melakukan proses metabolisme.

c) Adanya pengaruh air tawar yang masuk ke dalam perairan, baik melalui hujan dan atau melalui muara sungai yang ada di daratan utama Kabupaten Pamgkep. Untuk kondisi ketiga dan keempat, hal itu dimungkinkan untuk terjadi karena 
wilayah perairan Pulau Polewali bera berada dekat dengan daratan utama (mainland yang memilliki beberapa muara-muara sungai cukup banyak yang menjadi penyuplai sedimen dari daratan utama.

d) Masih lemahnya pengawasan di beberapa titik karang gosong (patch reef) yang menjadi lokasi favorit daerah penangkapan ikan (fishing ground) para nelayan pengrusak seperti di beberapa titik lokasi penelitian.

\section{i. Strategi Pengelolaan Terumbu Karang}

Perumusan strategi pengelolaan untuk ekosistem terumbu karang di lokasi penelitian didasarkan pada analisis kekuatan (strength), kelemahan (weakness), peluang (opportunity) dan ancaman (threat).

Tabel 2. Hasil Pembobotan dan Rating Faktor Internal

\begin{tabular}{llccc}
\hline & \multicolumn{1}{c}{ IFAS } & Bobot & Rating & Skor \\
\hline S1 & \multicolumn{1}{c}{ Kualitas perairan yang masih relatif baik } & 0,10 & 2 & 0,20 \\
\hline S2 & $\begin{array}{l}\text { Kondisi karang yang masih bagus dan keanekaragaman } \\
\text { jenis karang yang banyak dijumpai }\end{array}$ & 0,15 & 4 & 0,60 \\
\hline S3 & $\begin{array}{l}\text { Memiliki Biota Dilindungi Yang Hampir Punah Yakni } \\
\text { Penyu }\end{array}$ & 0,15 & 4 & 0,60 \\
\hline S4 & $\begin{array}{l}\text { Gosong-Gosong Karang di Pulau Cangke dan Pulau } \\
\text { Polewali dijadikan sebagai daerah kawasan konservasi }\end{array}$ & 0,08 & 2 & 0,16 \\
\hline S5 & $\begin{array}{l}\text { Pencadangan KKPD Liukang Tuppabiring Melalui SK } \\
\text { Gubernur Sulawesi Selatan Tahun 2018sangat kurang }\end{array}$ & 0,13 & 4 & 0,52 \\
\hline & \multicolumn{1}{c}{ Kelemahan } & 3 & 0,21 \\
\hline W1 & $\begin{array}{l}\text { Kurangnya keanekarangaman jenis ikan karang yang } \\
\text { memiliki nilai ekonomis penting }\end{array}$ & 0,07 & 0,18 \\
\hline W2 & $\begin{array}{l}\text { Kurangnya pengawasan dan lemahnya penegakan } \\
\text { hukum serta lembaga masyarakat yang belum ada }\end{array}$ & 0,09 & 2 \\
\hline W3 & $\begin{array}{l}\text { Belum ditetapkannya KKPD Tuppabiring sebagai } \\
\text { kawasan konservasi }\end{array}$ & 0,05 & 3 & 0,15 \\
\hline W4 & $\begin{array}{l}\text { Lembaga Pengelola KKPD Tuppabiring masih belum } \\
\text { jelas }\end{array}$ & 0,05 & 3 & 0,15 \\
\hline W5 & $\begin{array}{l}\text { Rencana Zonasi Pengelolaan terumbu karang belum } \\
\text { ada }\end{array}$ & 0,13 & 3 & 0,39 \\
\hline
\end{tabular}

Tabel 3. Hasil Pembobotan dan Rating Faktor Eksternal (EFAS)

\begin{tabular}{llccc}
\hline \multicolumn{1}{c}{ EFAS } & Bobot & Rating & Skor \\
\hline P1 & \multicolumn{1}{c}{$\begin{array}{l}\text { Dukung } \\
\text { Pengelolaan Terumbu Karang }\end{array}$} & 0,16 & 4 & 0,64 \\
\hline O2 & $\begin{array}{l}\text { Gosong Karang Pulau Cangke dan Pulau Polewali } \\
\text { sebagai bank benih ikan (stock) untuk meningkatkan } \\
\text { hasil tangkapan }\end{array}$ & 0,16 & 3 & 0,48 \\
\hline
\end{tabular}




\begin{tabular}{clccc}
\hline O3 & $\begin{array}{l}\text { Dukungan Pemerintah dalam pengembangan KKPD } \\
\text { Liukang Tuppabiring }\end{array}$ & 0,16 & 4 & 0,64 \\
\hline \multicolumn{1}{c}{ Ancaman } \\
\hline T1 & $\begin{array}{l}\text { Degradasi ekositem terumbu karang akibat alat } \\
\text { tangkap destruktif }\end{array}$ & 0,16 & 3 & 0,48 \\
\hline T2 & $\begin{array}{l}\text { Konflik kepentingan terkait wilayah penangkapan } \\
\text { ikan }\end{array}$ & 0,13 & 3 & 0,39 \\
\hline T3 & $\begin{array}{l}\text { Kegiatan yang berpotensi menimbulkan pencemaran } \\
\text { dan kerusakan lingkungan }\end{array}$ & 0,10 & 3 & 0,30 \\
\hline T4 & Perubahan iklim akibat pemanasan global & 0,13 & 3 & 0,39 \\
\hline
\end{tabular}

Berdasarkan ranking prioritas

4. Melakukan monitoring dan evaluasi strategi pengelolaan yang telah dilakukan dididapatkan 9 kebijakan strategi pengelolaan terumbu karang di Pulau Cangke dan Pulau Polewali yang merupakan bagian dari KKPD Liukang Tuppabiring dan sekitarnya sebagai berikut :

1.Pengelolaan terumbu karang yang ramah lingkungan dimana masyarakat sebagai pengelola dengan dukungan kuat dari Pemerintah.

2. Membuat aturan yang jelas terkait pemanfaatan di kawasan terumbu karang serta membentuk lembaga POSMAKWAS di KKPD Tuppabiring untuk menghindari kerusakan karang yang lebih parah.

3. Meningkatkan pengawasan dan penegakan hukum harus tegas terkait penggunaan alat tangkap yang dapat merusak ekosistem terumbu karang, serta Memberikan pelatihan dan penyuluhan serta pemahaman kepada masyarakat akan pentingnya nilai ekonomi dan ekologi ekosistem terumbu karang. terhadap kondisi biofisik serta sosail budaya secara terpadu dan berkesinambungan.

5. Melakukan konsultasi publik kepada masyrakat untuk persetujuan perairan Liukang Tuppabiring sebagai kawasan konservasi

6. Adanya legimitasi berupa peraturan terkait pengelolaan ekosistem terumbu karang melalui penetapan kawasan konservasi perairan di KKPD Tuppabiring.

7. Membatasi dan mengurangi aktivitas di kawasan terumbu karang dengan cara pembuatan/penetapan zonasi pengelolaan terumbu karang.

8. Melakukan upaya kegiatan rehabilitasi ekosistem terumbu karang yang telah mengalami kerusakan dengan metode transpalantasi karang.

9. Mengurangi bahan pencemar masuk ke perairan.

\section{KESIMPULAN}

1. Kondisi terumbu karang di 6 stasiun pengamatan masuk dalam kategori 
sedang dengan nilai rata-rata persentase karang hidup 39,33\%. Karang dengan kategori baik (56\%) terdapat di stasiun 5 Pulau Cangke, karang dengan kategori sedang dijumpai di stasiun 1 dan 2 Pulau Polewali serta stasiun 3, 4 dan 6 Pulau Cangke (25,47-41\%). Sementara itu kondisi sumberdaya ikan karang di di lokasi penelitian masuk dalam kategori banyak (100 individu ikan target).

2. Terumbu karang pada gosong karang di Pulau Cangke dan Pulau Polewali secara visual masih dalam kondisi yang cukup baik akan tetapi di beberap titik juga banyak ditemukan karang yang telah mengalami kerusakan cukup parah. Faktor utama yang mejadi penyebab kerusakan adalah penggunaan alat tangkap ikan yang sifatnya merusak seperti bom maupun racun serta alat tangkap yang tidak ramah lingkungan, selain itu tidak adanya aturan pengelolaan yang bersifat lokal ikut andil bagi terjadinya kerusakan terumbu karang di wilayah ini.

3. Strategi utama pengelolaan terumbu karang yang dapat dilakukan di Pulau Cangke dan Pulau Polewali adalah sebagai berikut:

- Pengelolaan terumbu karang yang ramah lingkungan dimana masyarakat sebagai pengelola dengan dukungan kuat dari Pemerintah.

- Membuat aturan yang jelas terkait pemanfaatan di kawasan terumbu karang serta membentuk lembaga POSMAKWAS di KKPD Liukang Tuppabiring untuk menghindari kerusakan karang yang lebih parah.

- Meningkatkan pengawasan dan penegakan hukum harus tegas terkait penggunaan alat tangkap yang dapat merusak ekosistem terumbu karang, serta Memberikan pelatihan dan penyuluhan serta pemahaman kepada masyarakat akan pentingnya nilai ekonomi dan ekologi ekosistem terumbu karang.

\section{SARAN}

1. Perlu penelitian lebih lanjut tentang tingkat partisipasi masyarakat serta faktor-faktor yang mempengaruhi dalam pengelolaan terumbu karang di perairan Pulau Cangke dan Pulau Polewali

2. Pemerintah Propinsi Sulawesi Selatan harus segera menetapkan KKPD Tuppabiring menjadi sebuah kawasan konservasi agara keanekaragaman ekosistem serta sumberdaya ikan yang terdapat di perairan ini dapat segera terlindungi. 


\section{UCAPAN TERIMA KASIH}

Hasil kajian ini merupakan bagian dari penelitian Tesis dan penulis mengucapkan terima kasih kepada para dosen pembimbing dan dosen penguji, dan team dari Deco yang telah banyak membantu dalam penelitian ini. Peneliti juga mengucapkan banyak terimah kasih kepada Ketua Prodi Manajemen Pesisir dan Teknologi Kelautan serta Direktur Pasca Sarjana yang telah memberi kesempatan untuk melanjutkan pendidikan di PPS UMI.

\section{DAFTAR PUSTAKA}

[BPS] Badan Pusat Statistik Kabupaten Pangkajene dan Kepulauan. 2019. Kecamatan Liukang Tuppabiring Dalam Angka 2019. Badan Pusat Statistik. Pangkajene dan Kepulauan.

David, F. R. 2009. Manajemen Strategis. Penerbit Salemba Empat. Jakarta.

Giyanto, B.H., Iskandar, D., Soedharma \& Suharsono. 2010. Effisiensi dan akurasi pada proses analisis foto bawah air untuk menilai kondisi terumbu karang. Oseanologi dan Limnologi di Indonesia 36 (1): 111-130.

Giyanto. 2012a. Kajian tentang panjang transek dan jarak antar pemotretan pada penggunaan metode transek foto bawah air.
Oseanologi dan Limnologi di Indonesia 38 (1): 1-18.

Giyanto. 2012b. Penilaian kondisi terumbu karang dengan metode transek foto bawah air. Oseanologi dan Limnologi di Indonesia 38 (3):377-389

Gomez, E.D. and H.T. Yap, 1988. Monitoring reef condition In: R.A. Kenchington \& B.E.T. Hudson (eds). Coral Reef Management handbook, UNESCO Jakarta: 187195.

Keputusan Menteri Negara Lingkungan Hidup (Kepmen LH) Nomor 51 Tahun 2004. Tentang Baku Mutu Air Laut. Jakarta.

Keputusan Gubernur Sulawesi Selatan Nomor 3172/XII/Tahun 2018 TentangPencadangan Kawasan Konservasi Perairan Daerah Wilayah Liukang Tuppabiring dan Perairan Kecamatan Liukang Tangaya Di Kabupaten Pangkajene dan Kepulauan Provinsi Sulawesi Selatan.

Manuputty, A.W.E., Djuwariah. 2009. Panduan Metode Point Intercept Transect (PIT) Untuk Masyarakat. Coral Reef Rehabilitation and Management Program. Lembaga Ilmu Pengetahuan Indonesia. Jakarta.

Manuputty, A.W.E. 2012. Ekosistem Pesisir Perairan Pangkajene Kepulauan Propinsi Sulawesi Selatan. Pusat Penelitian Oseanografi. Lembaga Ilmu Pengetahuan Indonesia. Jakarta.

Partini. 2009. Efek Sedimentasi Terhadap Terumbu Karang Di Pantai Timur Kabupaten Bintan. Tesis. Sekolah Pascasarjana. Institut Pertanian Bogor. Bogor. 